\title{
Sensitivity to Atypical Mycobacterial Antigens in Patients with Crohn's Disease
}

\author{
Joel Morganroth, BS and David W. Watson, MD
}

\begin{abstract}
Twenty-two patients with Crohn's disease were investigated for the presence of delayed cutaneous reactions and precipitating antibodies to atypical mycobacterial antigens of Runyon's Groups I, II and III as well as standard PPD. The results obtained, when compared to the control groups, do not show an increased incidence of sensitivity to such antigens in patients with Crohn's disease. However, their potential relevance to the pathogenesis of this disorder remains to be determined.
\end{abstract}

Since Croln's original description (1) of a granulomatous disorder involving the terminal ileum, distinct from ileocecal tuberculosis, little has been done to elucidate its cause. This is both curious and unfortunate, for its distribution, pathologic features and patterns of recurrence suggest numerous possibilities for investigation. The presence of granulomas has invited comparison with disorders exhibiting similar lesions such as tuberculosis, berylliosis, the deep mycoses and sarcoidosis, but no convincing parallels have emerged.

Speculation has in the main centered around either an infectious or an immune origin. Attempts to isolate an infectious agent have been umrewarding but limited, being confined largely to mycobacterium tuberculosis and certain viruses (2). Although there is little to suggest an immune

From the University of Michigan Medical Center, Ann Arbor, Mich.

Address for reprint requests: Dr. D. Watson, Department of Medicine, University of Michigan Medical Center, Inn Arbor, Mich 48104. etiology for this clisorder, granulomas may in some situations constitute morphologic evidence of an immune response. The granulomatous reaction to tubercle bacilli and many fungi has long been understood as a manifestation of delayed hypersensitiv. ity; more recently the tissue response in schistosomiasis has been shown to have a similar basis (3). Still, no organism capable of initiating such an immune response has been found in affected tissues, nor have tissues exhibiting granulomas been shown to contain antigens capable of eliciting an immune response in patients with Crohn's clisease (4).

Although the comparison with sarcoid. osis, another chronic granulomatous disorder of unknown cause, is somewhat strained, the recent finding that anonymous mycobacteria could be cultured from the tissues of such patients with mycobacteriophage-neutralizing antisera has obvious potential relevance $(5,6)$. It would therefore be of interest to know whether infection by such organisms was more fre- 
quent in individuals with Crohn's disease than in the population at large. If true, such patients might be expected to exhibit either delayed cutaneous reactions or humoral antibodies to these mycobacterial antigens.

\section{MATERIALS AND METHODS}

Twenty-two patients with Crohn's disease were investigated for the presence of precipitins or delayed cutaneous reactions to atypical mycobacterial antigens of Runyon's Groups I, II and III as well as PPD. Only patients with typical radiologic or histologic features were included. Skin test controls were derived from two sources: (l) student nurses at the University of Michigan who formed part of a study carried out by the Pulmonary Disease Section of the Department of Medicine, and (2) white navy recruits, aged 17-21 years, tested as part of the USPHS-USN cooperative skin test program (7). The atypical mycobacterial antigens were obtained from the National Communicable Disease Center and contained $0.0001 \mathrm{mg} / 0.1 \mathrm{mI}$ (skin test dose). Standard intermediate strength PPD was utilized as an additional control. All skin tests were carried out on the volar aspect of the forearm and were read at $48 \mathrm{hr}$. At this time the diameter of any induration was measured. No patients were on corticosteroids or immunosuppressives. Before the skin tests were applied, blood was obtained for double gel diffusion studies by the standard microscopic slide technic using the same antigens used for skin testing.

\section{RESULTS}

\section{Control Group}

The USPHS-USN cooperative skin test program tested 14,261 Michigan naval recruits, aged 17-21, with PPD-S and PPD-B in a manner identical to that employed in this study. Induration of $4 \mathrm{~mm}$ or more at $48 \mathrm{hr}$ in response to PPD-S was found in $4.4 \%$ while $15.5 \%$ manifested $4 \mathrm{~mm}$ or more of induration upon being tested with PPD-B. The criteria for quantitating the dermal reactions were chosen simply to separate those who react to the test from those who do not. No other interpretation based upon magnitude of response was attempted. Most reactions to PPD-B (Group II) probably represent cross reactions to still unidentified mycobacterial infections as do minimal (less than $10 \mathrm{~mm}$ ) reactions to $\mathrm{PPD}-\mathrm{S}$. Therefore, one cannot use the results in our two control groups or our patient group to derive information concerning specific infection with a given mycobacterium; rather, one should use a general index of exposure to many mycobacterial antigens which is in fact the objective of this study.

In the nursing students, reactions of 5 $\mathrm{mm}$ or more of induration were found in $3.6 \%$ (of 368) tested with PPD-S; $20.1 \%$ (of 167) tested with PPD-B (Group II) and $51.1 \%$ (of 20I) tested with PPD-G (Group III). The navy recruits were not tested with PPD-G. These results are summarized in Table 1.

\section{Test Group}

Eighteen percent of the patients with Crohn's disease (4 of 22) exhibited $5 \mathrm{~mm}$ or more of induration to PPD-S. None of the 22 reacted to PPD-Y (Group I) while $13.6 \%$ (3 of 22) responded with $5 \mathrm{~mm}$ or more of induration to both PPD-B and PPD-G. None of the 14 patients whose sera were tested had precipitating antibodies to any of the four.antigens as measured by double gel diffusion. The results of the studies carried out in the patient group are tabulated in Table 2.

\section{DISCUSSION}

Although microbiologic studies in Crohn's disease have failed to support an infectious etiology, the extent of most investigations has been limited. The fact that organisms cannot be demonstrated in diseased tissue by either direct staining or cultural technic does not constitute proof 
of their absence. A case in point is sarcoidosis. Mycobacteriophages, demonstrated in the stools and tissues of patients

Table 1. Dermal Sensitivity in Control Groups

\begin{tabular}{ccc}
\hline & \multicolumn{2}{c}{$\begin{array}{c}\text { Percent of subjects with } \\
\text { induration }>4 \mathrm{~mm}\end{array}$} \\
Antigen & USPHS-USN study Student nurses \\
\hline PPD-S & $4.4(14,261)^{*}$ & $3.6(368)^{*}$ \\
PPD-B & $15.5(14,261)^{*}$ & $20.1(167)^{*}$ \\
PPD-G & - & $51.1(201)^{*}$ \\
\hline
\end{tabular}

PPD.S, standard PPD; PPD-B, Group II; and PPD-G, Group III.

* Numbers in parentheses indicate number of subjects tested.

Table 2. Immune Response in Patients with Crohn's Disease

\begin{tabular}{|c|c|c|c|c|}
\hline Patients & $\begin{array}{l}\text { Age } \\
(y r)\end{array}$ & Sex & Skin test & DGD* \\
\hline$J T$ & 13 & M & All negative & Not tested \\
\hline AW & 35 & $\mathrm{~F}$ & $\begin{array}{l}\text { Group II, III } \\
(0.5 \mathrm{~cm})\end{array}$ & All negative \\
\hline $\mathrm{FL}$ & 50 & $\mathrm{~F}$ & PPD $(0.5 \mathrm{~cm})$ & Not tested \\
\hline FB & 28 & $M$ & All negative & Not tested \\
\hline ET & 49 & $F$ & $\begin{array}{c}\text { Group II, III } \\
(0.5 \mathrm{~cm})\end{array}$ & Not tested \\
\hline MK & 22 & $\mathrm{~F}$ & All negative & Not tested \\
\hline$J B$ & 25 & $\mathbf{F}$ & PPD $(0.5 \mathrm{~cm})$ & Not tested \\
\hline CG & 25 & $\mathrm{~F}$ & All negative & Not tested \\
\hline WW & 50 & $\mathrm{~F}$ & All negative & Not tested \\
\hline NL & 48 & $\mathrm{~F}$ & All negative & All negative \\
\hline WG & 20 & $M$ & All negative & All negative \\
\hline BS & 42 & $\mathrm{~F}$ & All negative & All negative \\
\hline SD & 38 & M & PPD $(0.5 \mathrm{~cm})$ & All negative \\
\hline DS & 19 & $M$ & All negative & All negative \\
\hline $\mathrm{EH}$ & 54 & $\mathrm{~F}$ & All negative & All negative \\
\hline$K B$ & 50 & $\mathrm{~F}$ & All negative & All negative \\
\hline DL & 22 & $M$ & All negative & All negative \\
\hline $\mathrm{JC}$ & 26 & $M$ & All negative & All negative \\
\hline RW & 25 & $M$ & All negative & All negative \\
\hline ZG & 20 & $M$ & All negative & All negative \\
\hline IP & 46 & $\mathrm{~F}$ & All negative & All negative \\
\hline $\mathrm{CC}$ & 54 & $M$ & $\begin{array}{l}\text { PPD, Group } \\
\text { II, III } \\
(0.5 \mathrm{~cm})\end{array}$ & All negative \\
\hline
\end{tabular}

* DGD, double gel diffusion. with sarcoidosis, are capable of converting mycobacteria to a lysogenous state wherein they can be neither seen nor cultured (8) . Patients with tuberculosis also harbor mycobacteriophages, but in addition possess phage-neutralizing antibodies. Such antibodies are not found in patients with sarcoidosis. When tissues from patients with sarcoidosis are cultured in the presence of phage-neutralizing antibodies, atypical mycobacterial strains can frequently be recovered $(5,6)$. Furthermore, the simultaneous infection of guinea pigs with tubercle bacilli and mycobacteriophages produces a sarcoid-like lesion from which atypical mycobacteria can be recovered (9). These findings led Mankiewicz and Beland to postulate that sarcoidosis might result from infection with these atypical organisms wherein a transient overt stage was followed by a lysogenous stage; therefore, mycobacteria, even though present, could not be demonstrated.

That a similar situation might exist in patients with Crohn's disease is a possibility worth considering. Although sarcoidosis and Crohn's disease appear to be entities distinct from one another, certain points of similarity do exist. They are both chronic granulomatous disorders of obscure origin, and anergy for delayed hypersensitivity has been associated with both. While firmly established for sarcoidosis, such anergy continues to be debated in the case of Crohn's disease. The results of some studies support the existence of anergy (4) while others do not (10). The best controlled and most convincing study, that of Fletcher and Hinton (10), suggest that anergy is not characteristic of patients with Crohn's disease. It should be remembered, however, that even in sarcoidosis, anergy is not complete; some antigens continue to elicit delayed hypersensitivity reactions in a normal manner.

A further point of similarity between the 
two disorders is the recent finding that approximately one-half of patients with Crohn's disease develop a positive reaction to the Kveim antigen (11). Previous studies of the Kreim reaction in Crohn's disease have been negative (4). Mitchell et al point out, however, that biopsies were not done and smaller amounts of test material were employed in the studies yielding negative results.

In view of these similarities between Crohn's disease and sarcoidosis and the finding of atypical mycobacterial species in the latter, it seemed worthwhile to determine whether patients with Crohn's disease demonstrated more frequent cutaneous or serologic reactions to atypical mycobacterial antigens than controls.

The results of this study indicate that no increase in delayed cutaneous responses is present in such patients in comparison with control groups. Furthemore, no circulating antibodies could be demonstrated to these antigens by the clouble gel diffusion technic.

Alternative interpretations of these results are possible. First, tissue involvement with atypical mycobacteria may not be characteristic of patients with Crohn's disease. Dermal reactivity would likely be present if such were the case. However, mycobacteria other than the ones utilized in this study might be responsible. If so, one must assume they are not cross-reactive with Runyon's Groups I, II or III or standard PPD. There is also no certainty that such antigens existing in a lysogenous state are immunogenic. Second, these results would be consistent with a state of anergy to the antigens employed. This possibility cannot be excluded although the results of Fletcher and Hinton's study would appear to make this unlikely. The recent demonstration that patients with Crohn's disease are less susceptible to primary sensitization with 2,4 dinitrochlorobenzene than normal controls (12) may, however, alter this belief. It may be that while established delayed hypersensitivity is not interfered with, there is an impairment in the ability to acquire such sensitivity after the advent of Crohn's clisease.

Although the results of the present study do not support a role for atypical mycobacterial organisms of Runyon's Groups I, II or III in the pathogenesis of Crohn's disease, the possibility that some obscure mycobacterial species may play such a role should not be prematurely abandoned. It is perhaps noteworthy that azulfidine may have a beneficial effect on the course of Crohn's disease. This medication contains a 5-amino salicylic acid moiety as well as a sulfapyridine molecule similar to the tuberculostatic drug PAS. Sulphones, analogues of $p$-aminobenzoic acid, sulphonamides and aminosalicylic acid are effective in mycobacterial disorders such as leprosy (13).

It would be worthwhile to attempt to isolate atypical mycobacterial organisms from the affected tissues of patients with Crohn's disease, utilizing antimycobacteriophages in the culture system.

\section{REFERENCES}

1. Crohn BB, Ginzburg L, Oppenheimer GD: Regional ileitis. JAMA 99:1323-1329, 1932

2. Kyle J, Bell T.M, Porteous JB, et al: Factors in the etiology of regional enteritis. Bull Soc Int Chir 22:575-584, 1963

3. Warren KS, Domingo EO, Cowan RBT: Granuloma formation around schistosome eggs as a manifestation of delayed hypersensitivity. Amer J Path 51:735-756, 1967

4. Williams WJ: A study of Crohn's syndrome using tissue extracts and the Kveim and Mantoux tests. Gut 6:503-505, 1965

5. Berger HW, Zaldivar C. Chusid EL: Anonymous mycobacteria in the etiology of sarcoidosis. Ann Int Med 68:872-874, 1968 
6. Mankiewice l: The relationship of sarcoidosis to anonymous mycobacteria. Acta Med Sand I76:Suppl 425:68-73, 1964

7. Eelwards I.B, Acquaviva FA, Livesay VI, ct al: An atlas of sensitivity to tuberculin, PPD-B and histoplasmin in the United States. Amer Rev Resp Dis 99:56-57, part 2, 1969

8. Mankiewicz l, van Walbeek M: Mycobacteriophages: their role in tuberculosis and sarcoidosis. Arch linviron Health (Chicago) $5: 122-128,1962$

9. Mankiewice E, Beland J: The role of mycobacteriophages and of cortisone in experi- mental tuberculosis and sarcoidosis. Iner Rer Resp Dis 89:707-720, 1964

10. Fletcher J, Hinton JM: Tuberculin sensitivity in Crohn's discase. Lancet 2:753-754, 1967

11. Mitchell DN, Camnon P, Dyer NH, et al: The Kreim test in Crohn's disease. Lancet 2:571-573, 1969

12. Verrier Jones $J$, Housley J, Ashurst $\mathbf{P}$, et al: Development of delayed hypersensitivity to dinitrochlorobenzene in patients with Crohn's disease. Gut 10:52-56, 1969

13. Goldie DW, McGill C.M: Aetiology of regional enteritis. Lancet 1:1144-1145, 1968 